\title{
Evaluación de la sustentabilidad de los sistemas productivos campesinos de la Asociacion de Caficultores Orgánicos de Colombia - ACOC- Valle del Cauca
}

\author{
Gloria Inés Cárdenas Grajales ${ }^{1}$ - Álvaro Acevedo Osorio ${ }^{2}$
}

Recepción: 26/07/2015

Aceptación: 28/08/2015

\section{Resumen}

El estudio presenta los resultados del estado y desempeño de la sustentabilidad de sistemas productivos de la Asociación de Caficultores Orgánicos de Colombia ACOC, mediante once indicadores locales relacionados con los recursos y la operación del sistema, comparando resultados para dos ciclos de evaluación en 2005 y 2010.

Las evaluaciones se hicieron de manera participativa con treinta familias campesinas de la ACOC, utilizando la metodología MESMIS - Marco para la Evaluación de Sistemas de Manejo de Recursos Naturales Incorporando Indicadores de Sustentabilidad. Para el análisis estadístico se construyó un plano factorial con once variables activas de tipo categórico, una variable categórica ilustrativa de cuatro localidades: Restrepo, Buga, Riofrío y el corregimiento de Fenicia, y una variable continua ilustrativa correspondiente a los Índices de Sustentabilidad. Los resultados presentaron reducciones del 1.8\% y del 15.8\% para los grupos 1 y 3 , respectivamente; y un aumento del 13.2\% para el grupo 2. Los indicadores que mayor variabilidad presentaron fueron Agrodiversidad sustentable, Biodiversidad y Autosuficiencia Alimentaria. En general los cambios en los indicadores fueron leves, mostrando que la sustentabilidad de los sistemas productivos de la ACOC tuvo un comportamiento equilibrado durante los cinco años que transcurrieron entre las dos evaluaciones.

Palabras clave: Indicadores, sustentabilidad, MESMIS, Asociación de Caficultores Orgánicos de Colombia, Caficultura.

\begin{abstract}
Indicators establish a very useful tool to evaluate in a near way the sustainability of agriculture, from a multidimensional focus that integrates ecologic, economical, sociable, cultural, and political variables, interacting in a specific agro ecosystem. The study presents the results of the state and performance in the sustainability of productive systems of the Association of Organic Coffee Growers of Colombia AOCGC, by means of eleven local indicators related to the resources and operation of the system, contrasting the results of two cycles of evaluation in 2005 and 2010.
\end{abstract}

The evaluations were made in an interactive way with thirty peasant families of the AOCGC, using MESMIS methodology - Framework to Assess the Sustainability of Alternative Natural Resource Management Systems. For the statistical analysis, there was created a factorial plane with eleven active, categorical variables, one illustrative categorical variable of four locations: Restrepo, Buga, Riofrío, village of Phoenicia, and an illustrative continuous variable to the Sustainability Indexes. The results presented cutbacks from $1.8 \%$ to $15.8 \%$ for the groups 1 and 3, accordingly; and an increase of 13.2\% for the group 2. The indicators that presented the greatest variation were sustainable agro diversity, biodiversity, and alimentary self-sufficiency. In general, the changes on the indicators were not meaningful, showing that the sustainability of the productive systems of the AOCGC had a balanced behavior throughout the five years that passed among the two evaluations.

Key words: indicators, sustainability, MESMIS, Association of Organic Coffee Growers of Colombia, coffee cultivation

1. Docente Asociada Facultad Ciencias Administrativas y Desarrollo Rural UNISARC. Grupo de Investigación en Estudios Rurales contextualizados al Territorio. Directora Especialización en Agroecología Tropical Andina. Santa de Rosa de Cabal - Risaralda - Colombia. agroecología@unisarc.edu.co

2. Docente e Investigador. Programa de Ingeniería Agroecológica, UNIMINUTO. Grupo de Investigación Agroeco y Gestión Ambiental. Bogotá - Colombia. alacevedo@uniminuto.edu 


\section{Introducción}

El Desarrollo Sustentable emerge desde la década de 1980 como un paradigma que intenta incidir en un manejo holístico, multisistémico y multicriterial de los recursos naturales, el diseño de sistemas de producción y la formulación de programas y políticas públicas. Abordar la sustentabilidad desde un enfoque multidimensional y como el resultado del interjuego de variables ecológicas, económicas, sociales, culturales y políticas (Benton, 1994, citado por Cáceres 2008) implica reconocer la complejidad del concepto y asumir la necesidad de comprender la realidad desde el análisis de las interacciones, que ocurren entre la naturaleza y la sociedad (Clarck, 2007; citado por Cáceres 2008). Esto requiere una comprensión sistémica de los problemas que le subyacen y pone de manifiesto la necesidad de analizarla desde perspectivas multidisciplinarias (Constanza y Patten, 1995, citados por Toro et al., 2010).

La idea de sustentabilidad está siendo adaptada a cada campo específico de la acción humana. Los que hablan del crecimiento económico defienden la idea de que es posible mantener la producción con un crecimiento constante, conservando la capacidad productiva de la base de recursos naturales; los que esgrimen el desarrollo sustentable como la satisfacción de las necesidades tanto de las poblaciones presentes como de las futuras, enfatizan en la condición de la equidad intra e intergeneracional y final- mente están los que alegan la imposibilidad del crecimiento económico ilimitado; y en ese sentido, la sustentabilidad no podría ser posible a menos que exista un acceso equitativo de las sociedades a los bienes y recursos del planeta (Acevedo, 2000).

De esta forma, el concepto de sustentabilidad se ha convertido en un nuevo paradigma en el discurso sobre el desarrollo (Toro et ál, 2010; Astier, Masera y Galván-Miyoshi, 2008; Masera, Astier y López-Ridaura, 1999); sin embargo, la manera de hacer operativo el concepto no es aún clara, por lo que se percibe como abstracto, de difícil concreción en la práctica, con el riesgo de que no logre ese cambio estructural que requieren los programas de desarrollo. Existe la necesidad de transformar el concepto de sustentabilidad en definiciones y estrategias operacionales que puedan ser utilizadas para evaluar el impacto de distintas acciones en la sustentabilidad de los sistemas (López-Ridaura, Masera y Astier, 2002).

Ejercicios de evaluación de sustentabilidad en Colombia han sido abordados por Acevedo (2000), Acevedo \& Angarita (2013); CIPAV; PNUD; CEPAL y el Sistema Nacional Ambiental. En América Latina se destacan los trabajos realizados por Astier y Masera (1996), Cáceres (2008), Delgadillo y Delgado (2003), Cardoza (2003), Gomes de Almeida (2003), Petersen (2003), Toro et al. (2010); Fallas et al. (2009), entre otros. 
En el año 2005 se realizó la primera evaluación de la sustentabilidad en la Asociación de Caficultores Orgánicos de Colombia ACOC; contó con la participación de las familias pertenecientes a la asociación, y se llevó a cabo en 110 fincas ubicadas en cinco localidades: Tuluá, Riofrío, Fenicia, Buga y Retrepo del departamento del Valle del Cauca (Colombia). La segunda evaluación se realizó cinco años después con 30 familias de la asociación que ya habían participado en el primer ciclo de medición.

El desarrollo de este proyecto acoge los aspectos centrales que comprende el concepto de sustentabilidad desde un enfoque de metaconcepto, que de acuerdo con Galván -Miyoshi, (2008) involucra multiplicidad de perspectivas válidas que dependen de un sistema de valores; implica entender la interrelación entre aspectos ambientales, económicos y sociales, e involucra la equidad intergeneracional articulando escalas temporales, espaciales e institucionales. El concepto se hace operativo desde el análisis de atributos generales de los sistemas como equidad, productividad, resiliencia, confiabilidad y otros, que permiten entender la capacidad de los socioecosistemas de ser productivos, autorregularse y transformarse para fortalecer los sistemas productivos.

Las mediciones de sustentabilidad en sistemas de producción campesinos - más allá del aporte teórico y metodológico al concepto - permiten poner en evidencia como el conocimiento y las prácticas tradicionales de los agricultores campesinos responden de manera diversa a las condiciones impuestas por el sistema económico, participando en procesos de permanentes cambios, producto del condicionamiento interno (Hernández, 1994). La agricultura campesina se evidencia en las diferentes maneras en que se ordena lo social y lo material; estos diferentes modos de ordenación afectan profundamente a la magnitud del valor agregado y su distribución, del mismo modo que a la naturaleza, la calidad y la sustentabilidad del proceso de producción, así como a los alimentos resultantes (Ploeg van der, 2010).

El presente estudio nació de la necesidad de conocer el nivel de sustentabilidad de los sistemas productivos campesinos de la Asociación de Caficultores Orgánicos de Colombia -ACOCy analizar su variación en el tiempo. El objetivo general fue evaluar la sustentabilidad de los sistemas productivos campesinos de la Asociación de Caficultores orgánicos de Colombia -ACOC- Valle del Cauca, mediante valoración de indicadores locales de sustentabilidad en dos momentos diferentes en el 2005 y el 2010.

Con el desarrollo de este proyecto se buscó aportar al conocimiento de la sustentabilidad de los sistemas de producción campesinos pertenecientes a la ACOC para reconocer los niveles de resiliencia y adaptación que les ha permitido mantenerse y permanecer en el tiempo pese a las presiones y restricciones que el modelo eco- 
nómico le genera a la producción campesina. Se espera con los resultados del estudio demostrar que, además de los beneficios prácticos, operativos, metodológicos y técnicos que ofrecen las distintas formas de medición de la sustentabilidad en diversas escalas, también contribuyen a demostrar la persistencia de las formas campesinas en contextos de desarrollo capitalista en América Latina (Hernández, 1994).

\section{Materiales y métodos}

El estudio se llevó a cabo en treinta fincas campesinas de la Asociación de Caficultores Orgánicos de Colombia ACOC, ubicadas en tres municipios y distribuidas de la siguiente manera: catorce en Riofrío; cinco en Buga; once en Restrepo.

ACOC es una organización sin ánimo de lucro constituida legalmente en 1992, cuya actividad principal es la producción y comercialización de productos orgánicos en especial el Café Orgánico con la marca Madremonte. Sus asociados son medianos y pequeños productores agropecuarios que trabajan en la producción, transformación y mercadeo de café y otros productos; aplicando el enfoque agroecológico con el propósito de mejorar la calidad de vida de los socios, sus familias y la comunidad. Sus actividades productivas buscan bajo impacto ambiental y los procesos organizativos de base comunitaria la han llevado a ser reconocida en la región como la organización campesina de mayor trayectoria en temas relacionados con agroecología.
Por más de diez años de existencia de ACOC, el trabajo agroecológico ha llevado a sus socios a consolidar los sistemas de producción en un contexto de biodiversidad, recuperación de saberes tradicionales, relaciones de reciprocidad y la recuperación de los espacios sociales y políticos que demanda la actualidad nacional e internacional (Grupo Semillas, 2004).

Se utilizaron como enfoques metodológicos la Investigación Participativa con Agricultores IPA (Fals-Borda \& Mohammad, 1991; Demo, 2009); y el Marco para la Evaluación de Sistemas de Manejo de Recursos Naturales Incorporando Indicadores de Sustentabilidad - MESMIS (Masera, et al, 1999), con las siguientes características:

- Se realizó en campo en el medio natural de los agricultores quienes participaron como investigadores comunitarios. Los resultados se obtuvieron y analizaron con la comunidad, el conocimiento adquirido fue compartido y socializado, lo que permitió un diálogo de saberes. El contexto participativo dio lugar a momentos de reflexión, conocimiento y autocrítica de los agricultores; se convocó a la iniciativa, al trabajo colectivo y a una revisión crítica de las situaciones analizadas.

- Se basó en la valoración del conocimiento que los agricultores tienen del entorno, los procesos productivos, su evolución en el tiempo y los saberes tradicionales. La me- 
todología adoptada implicó el estudio de individuos concretos en su ambiente social, donde se buscó conocer y comprender los pensamientos, los sentimientos y las experiencias, intentando interpretar los fenómenos de acuerdo con los significados y sentidos dados por los propios agricultores.

- El estudio involucró métodos cualitativos y se apoyó en resultados cuantitativos obtenidos por medio estadístico, específicamente usando del Análisis de Correspondencias Múltiples.

Las etapas de la Metodología MESMIS que se aplicaron en el estudio fueron:

1. Caracterización de los sistemas productivos: a través de la metodología de talleres participativos los agricultores construyeron la caracterización general de los sistemas productivos campesinos pertenecientes a la ACOC.

2. Identificación de puntos críticos de los sistemas de producción: el grupo identificó los puntos críticos entendidos como aquellos aspectos ambientales, técnicos, sociales o económicos que pueden tener un efecto crucial en la supervivencia del sistema; es decir, los factores donde el agroecosistema presenta problemas o es más vulnerable.

3. Construcción de Indicadores: a través de tres talleres participativos se logró la defi- nición de los once indicadores para llevar a cabo la medición de la sustentabilidad. Esta definición estuvo basada en los puntos críticos y mediante el siguiente derrotero: nombre del indicador, parámetros para su medición, forma de medirlo a nivel predial.

Estas etapas fueron aplicadas como etapas previas al inicio de las valoraciones de sustentabilidad propiamente dichas; a partir de estas, se hicieron dos ejercicios de valoración con cinco años de intervalo entre ellas, cada una de las cuales siguió las siguientes etapas:

4. Medición de cada indicador: La ficha de captura de información para los once indicadores se aplicó en treinta fincas de ACOC. En este proceso tomaron parte activa los miembros de la familia y en cada finca se realizó entrevista semi estructurada.

5. Obtención de los índices de sustentabilidad: asumido como el valor promedio de los valores individuales de cada indicador por finca.

6. Diagramación y análisis de resultados con agricultores: Los resultados de valoración de los once indicadores fueron diagramados para cada finca, empleando esquemas radiales o telarañas (Masera et al, 1999) para facilitar la comprensión y análisis de los resultados con cada grupo familiar.

Finalmente se realizó la comparación de los resultados de los índices de sustentabilidad en las 
dos evaluaciones 2005 - 2010; y los once indicadores usando el programa de estadística multivariada SPADN (Sistema Portable de Análisis de Datos Numéricos). Como las respuestas de las variables representan categorías, se utilizó la técnica de correspondencias múltiples, a través de la construcción de un plano factorial con once variables activas de tipo categórico, una variable categórica ilustrativa (municipios: Restrepo, Buga, Riofrío y el corregimiento de Fenicia), y una variable continua ilustrativa (Índice de Sustentabilidad). A partir de este modelo se determinó el número de valores propios (EIGENVALUE) a ser retenidos durante el análisis, considerándose que éste explicó al menos el $80 \%$ de la variabilidad encontrada. Luego se hizo el análisis de clúster para agrupar las fincas; con los grupos conformados se realizó también la estadística descriptiva de los once indicadores para cada grupo y una tipificación final.

\section{Resultados y discusión}

\section{Caracterización de los Sistemas Productivos de la ACOC}

Los sistemas productivos campesinos pertenecientes a la organización presentan áreas promedio entre 1 y 10 hectáreas con predominio del cultivo del café. La mano de obra es en su mayoría es familiar, los ingresos provienen casi exclusivamente de la finca y parte de la producción es dedicada al autoconsumo. La principal fuente de ingresos proviene de la venta de café orgánico, y en menor escala de la comercialización de plátano, frutas, cerdos, pollos, entre otros.
Las fincas se encuentran ubicadas en las dos vertientes de la cuenca del río Cauca entre los 1200 y 1 900m.s.n.m. con temperaturas promedio entre los 18 y $22^{\circ} \mathrm{C}$, con una precipitación que oscila entre los 1500 y $2500 \mathrm{~mm}$ por año. Los suelos de la zona se caracterizan por un relieve quebrado con pendientes entre el 30 y $80 \%$, presentando en algunas zonas limitantes por compactación, horizontes endurecidos y susceptibilidad a la erosión. Los contenidos de materia orgánica son variables entre el 5 y 12\% y presentan un $\mathrm{pH}$ ligeramente ácido.

Los sistemas productivos se caracterizan por una gran diversidad vegetal asociada al café y por su manejo orgánico. Las especies que predominan en arreglos multiestratos son: guamo (Inga spp), plátano (Musa spp), guayabo (Psidium spp), nogal cafetero (Cordia alliodora), vainillo (Tecoma stans), chachafruto (Erythrina edulis), cacao (Theobroma cacao), cítricos (Citrus spp), mango (Mangifera $s p p$ ), aguacate (Persea americana) y una gran cantidad de especies acompañantes silvestres. Las demás áreas están distribuidas en pastos para ganadería, bancos de proteínas, huertos de pancoger, cultivos semestrales como fríjol (Phaseolus spp) y maíz (Zea mays), rastrojos, zonas de protección y relictos de bosque andino. El 90\% de las variables de café son de porte bajo (caturra, variedad Colombia y Castillo) y un 10\% variedades de porte alto como Nacional y Borbón, las densidades de siembra se encuentran entre 2000 y 5 000 plantas por hectárea, y se implementan sis- 
temas de renovación por siembra, zoca y podas de diferente tipo.

Los sistemas de producción pecuaria son semiintensivos, la producción animal es diversa y representa una importante fuente de alimentos e ingresos económicos para las familias; además de la materia prima para la producción de abonos orgánicos. Predomina el ganado doble propósito, porcinos de ceba y cría, pollos de engorde, gallinas criollas, conejos y cuyes cuya alimentación está basada en la utilización de forrajes y leguminosas producidos en la finca como caña (Saccharum officinarum), bore (Alocasia macrorhyza), chachafruto (Erytrina edulis), nacedero (Trichantera gigantea) y pasto King-grass (Penisetum purpureum) entre otros.

La fertilización se realiza con abonos sólidos orgánicos tipo bocashi y biopreparados líquidos como biol, super 4, anaeróbico de estiércol bovino y super magro entre otros. Las prácticas agroecológicas están basadas fundamentalmente en el establecimiento de una diversidad apropiada y adaptada a las condiciones sociales, económicas y ecológicas de cada predio.

La mano de obra es mayoritariamente familiar y está basada en una distribución de labores características de los sistemas de producción campesinos; en algunas fincas es exclusivamente femenina. Existe una alta participación de la mujer en todos los ámbitos de la producción y de la organización, se da énfasis al trabajo asociativo como elemento de intercambio de conocimientos y fuerza laboral.
La producción es diversificada y dirigida al autoconsumo, al mercado local y a la exportación. Los mercados organizados de productos orgánicos diferentes a café son incipientes. Los productos comúnmente vendidos son: plátano (Musa spp), frutas, fríjol (Phaseolus spp), maíz (Zea mays), yuca (Manihot esculenta), arracacha (Arracacia xanthorrhiza), tomate de mesa (Lycopersicum esculentum), productos a partir de plantas medicinales, mermeladas, artesanías y miel de abejas.

\section{Identificación de los puntos críticos de los sis- temas de producción}

Los puntos críticos identificados por los agricultores de manera participativa dentro de cada componente fueron:

\section{Componente económico}
a. Dificultad en la comercialización de pro- ductos diferentes al café

- Escasez de recursos económicos

- Falta de ingresos diversificados

- Alta dependencia de insumos externos

- Baja productividad del café

- Falta de producción de excedentes para ofertar al mercado

- Disponibilidad de mano de obra escasa 


\section{b. Componente técnico-productivo}

- Escasa planificación de los cultivos

- Pocos conocimientos en procesos de poscosecha

- Alta incidencia de plagas y enfermedades

- No se hacen análisis de suelos

- Escasas fuentes de nutrición animal

- Falta de planificación y registros

- Falta de planes de fertilización

- Poca agrodiversidad

- No hay suficiente compromiso de los socios

\section{c. Componente sociocultural}

- Falta de aplicación de los conocimientos en producción agroecológica

- Falta de integración de la comunidad

- Seguridad alimentaria incipiente

- Pérdida de conocimientos y saberes ancestrales

- Pérdida de valores espirituales

- Subvaloración de lo que se tiene

- No hay integración de la familia al proceso

- Existen problemas de orden público

- No hay políticas claras por parte del gobierno para apoyar a los campesinos
- Influencia de las políticas macroeconómicas y creación de grandes mercados sobre la economía campesina

- Falta de conocimiento y conciencia del consumidor para exigir y demandar productos de alta calidad

- Falta de políticas orientadas a estimular el consumo de productos orgánicos

- Escasas políticas orientadas a la proyección de la organización

\section{d. Componente ambiental}

- Poca disponibilidad de agua en las fincas

- Manejo inadecuado de sólidos y líquidos

- Perdida de la biodiversidad

- Poca implementación de prácticas para la conservación de suelos, procesos erosivos intensos

- Desprotección de nacimientos y cuencas de agua

- Poca conciencia en la conservación de los recursos naturales

- Poca implementación de prácticas para el manejo de aguas residuales

- Pérdida de recursos genéticos locales 
Cada uno de los puntos críticos descritos fue analizado dentro del componente al que pertenecía, lo que permitió su reclasificación y selección, según la importancia dentro de la realidad de cada uno de los sistemas productivos bajo estudio. Los puntos críticos y las categorías de análisis con mayor trascendencia para el logro de condiciones de sustentabilidad se resumen en la figura 1:

\begin{tabular}{|c|c|c|}
\hline \multirow{2}{*}{ Elementos del sistema } & \multicolumn{2}{|c|}{ Categorías } \\
\hline & Recursos del sistema & Operación del sistema \\
\hline $\begin{array}{l}\text { Puntos críticos } \\
\text { para la sustentabilidad }\end{array}$ & $\begin{array}{l}\text { Componente ambiental } \\
\text { - Pérdida de biodiversidad } \\
\text { - Poca disponibilidad de agua } \\
\text { en las fincas } \\
\text { - Incrementos visibles en los ni- } \\
\text { veles de erosión de los suelos } \\
\text { - Pérdida de semillas tradicionales }\end{array}$ & $\begin{array}{l}\text { Componente económico } \\
\text { - Dependencia en alto grado de } \\
\text { ingresos provenientes de la ac- } \\
\text { tividad cafetera. } \\
\text { - Baja productividad del café } \\
\text { Componente técnico-productivo } \\
\text { - Carencia de esquemas de pla- } \\
\text { nificación productiva y regis- } \\
\text { tros para monitorear. } \\
\text { - Contaminación generada por } \\
\text { residuos sólidos y líquidos del } \\
\text { beneficio del café. } \\
\text { Componente sociocultural } \\
\text { - Poca participación de la fa- } \\
\text { milia en el complejo proceso } \\
\text { productivo. } \\
\text { - Deficiente grado de produc- } \\
\text { ción de alimentos para el sumi- } \\
\text { nistro familiar. } \\
\text { - Prevalencia de aplicaciones } \\
\text { técnicas basadas en conoci- } \\
\text { mientos técnicos. }\end{array}$ \\
\hline
\end{tabular}

Figura 1. Puntos críticos priorizados, componentes y recursos los sistemas 


\section{Construcción de los Indicadores}

Los puntos críticos e indicadores seleccionados para la evaluación de la sustentabilidad de las fincas de la ACOC fueron (figura 2):

\begin{tabular}{|c|c|c|c|c|c|}
\hline Punto crítico & $\begin{array}{l}\text { Nombre del } \\
\text { indicador }\end{array}$ & Concepto & \multicolumn{2}{|l|}{ Valoración } & $\begin{array}{l}\text { Cómo se } \\
\text { mide }\end{array}$ \\
\hline \multirow{5}{*}{$\begin{array}{l}\text { Baja productivi- } \\
\text { dad del café }\end{array}$} & \multirow{5}{*}{$\begin{array}{l}\text { Productividad } \\
\text { del café }\end{array}$} & \multirow{5}{*}{$\begin{array}{l}\text { Cantidad de café } \\
\text { pergamino seco } \\
\text { en arrobas por } \\
\text { plaza }^{3} \text { al año. }\end{array}$} & 80 o más @ de cps/plaza/año & 5 & \multirow{2}{*}{$\begin{array}{l}\text { Registros de } \\
\text { recolección }\end{array}$} \\
\hline & & & 60 a $79 @$ de cps/plaza/ año & 4 & \\
\hline & & & 40 a 59 @ de cps/plaza/año & 3 & \multirow{3}{*}{$\begin{array}{l}\text { Facturas de } \\
\text { venta }\end{array}$} \\
\hline & & & 20 a 39 @ de cps/plaza/año & 2 & \\
\hline & & & Menos19@de cps/plaza/año & 1 & \\
\hline \multirow{5}{*}{$\begin{array}{l}\text { Dependencia } \\
\text { en alto grado de } \\
\text { ingresos prove- } \\
\text { nientes de la ac- } \\
\text { tividad cafetera. }\end{array}$} & \multirow{5}{*}{$\begin{array}{l}\text { Ingresos diversi- } \\
\text { ficados }\end{array}$} & \multirow{5}{*}{$\begin{array}{l}\text { Cantidad o va- } \\
\text { riedad de ren- } \\
\text { glones produc- } \\
\text { tivos de carácter } \\
\text { comercial esta- } \\
\text { blecidos en la } \\
\text { finca }\end{array}$} & $\begin{array}{l}50 \% \text { de los ingresos por café }+3 \\
\text { renglones del } 50 \%\end{array}$ & 5 & \multirow{5}{*}{$\begin{array}{l}\mathrm{N}^{\circ} \text {. De cultivos } \\
\text { agrícolas o pe- } \\
\text { cuarios dife- } \\
\text { rentes al café }\end{array}$} \\
\hline & & & $\begin{array}{l}50 \text { al } 60 \% \text { por café }+3 \text { renglones } \\
\text { del } 40 \text { al } 50 \%\end{array}$ & 4 & \\
\hline & & & $\begin{array}{l}60 \text { al } 70 \% \text { por café }+2 \text { renglones } \\
\text { del } 30 \text { al } 40 \%\end{array}$ & 3 & \\
\hline & & & $\begin{array}{l}70 \text { al } 90 \% \text { por café }+1 \text { renglón del } \\
30 \text { al } 10 \%\end{array}$ & 2 & \\
\hline & & & $\begin{array}{l}\text { Se depende de un solo renglón } \\
\text { productivo }\end{array}$ & 1 & \\
\hline \multirow{5}{*}{$\begin{array}{l}\text { Carencia de } \\
\text { esquemas de } \\
\text { planificación } \\
\text { productiva y re- } \\
\text { gistros para mo- } \\
\text { nitorear }\end{array}$} & \multirow{5}{*}{$\begin{array}{l}\text { Planificación de } \\
\text { fincas y registros } \\
\text { de producción }\end{array}$} & \multirow{5}{*}{$\begin{array}{l}\text { Cantidad de } \\
\text { herramientas } \\
\text { necesarias para } \\
\text { ordenar, imple- } \\
\text { mentary evaluar } \\
\text { actividades en la } \\
\text { finca }\end{array}$} & $\begin{array}{l}\text { Diagnóstico predial, cronograma } \\
\text { de actividades, registro de com- } \\
\text { pras y ventas, costos de produc- } \\
\text { ción y diagrama de sustentabili- } \\
\text { dad }\end{array}$ & 5 & \multirow{5}{*}{$\begin{array}{l}\text { Verificación } \\
\text { de registros y } \\
\text { ejecución de } \\
\text { los mismos. }\end{array}$} \\
\hline & & & $\begin{array}{l}\text { Diagnóstico predial, cronograma } \\
\text { de actividades, registro de com- } \\
\text { pras y ventas }\end{array}$ & 4 & \\
\hline & & & $\begin{array}{l}\text { Diagnóstico predial, registro de } \\
\text { compras y ventas }\end{array}$ & 3 & \\
\hline & & & Registro de compras y ventas & 2 & \\
\hline & & & Solo registro de ventas & 1 & \\
\hline
\end{tabular}

3. La plaza es una unidad de superficie equivalente a 6400 metros cuadrados. 


\begin{tabular}{|c|c|c|c|c|c|}
\hline Punto crítico & $\begin{array}{l}\text { Nombre del } \\
\text { indicador }\end{array}$ & Concepto & \multicolumn{2}{|l|}{ Valoración } & $\begin{array}{l}\text { Cómo se } \\
\text { mide }\end{array}$ \\
\hline \multirow{5}{*}{$\begin{array}{l}\text { Pérdida de semi- } \\
\text { llas tradicionales }\end{array}$} & \multirow{5}{*}{$\begin{array}{l}\text { Agrodiversidad } \\
\text { sustentable }\end{array}$} & \multirow{5}{*}{$\begin{array}{l}\text { Cantidad de } \\
\text { especies agríco- } \\
\text { las y pecuarias } \\
\text { establecidas en } \\
\text { asociación en la } \\
\text { finca }\end{array}$} & $\begin{array}{l}8 \text { grupos con } 3 \text { spp vegetales y } 2 \\
\text { spp animales cada uno, (mínimo } \\
\text { una especie animal mayor) }\end{array}$ & 5 & \multirow{5}{*}{$\begin{array}{l}\text { Verificación } \\
\text { en campo }\end{array}$} \\
\hline & & & $\begin{array}{l}8 \text { grupos con } 2 \text { spp vegetales cada } \\
\text { uno y } 2 \text { spp animales cada uno }\end{array}$ & 4 & \\
\hline & & & $\begin{array}{l}4 \text { a } 6 \text { grupos con mínimo } 1 \mathrm{sp} \\
\text { animal mayor y } 2 \text { spp vegetales } \\
\text { cada uno }\end{array}$ & 3 & \\
\hline & & & 2 a 3 grupos con 2 spp cada uno & 2 & \\
\hline & & & $\begin{array}{l}2 \text { grupos con menos de } 2 \text { spp } \\
\text { cada uno }\end{array}$ & 1 & \\
\hline \multirow{5}{*}{$\begin{array}{l}\text { Poca partici- } \\
\text { pación de la } \\
\text { familia en el } \\
\text { complejo proce- } \\
\text { so productivo. }\end{array}$} & \multirow{5}{*}{$\begin{array}{l}\text { Integración } \\
\text { familiar }\end{array}$} & \multirow{5}{*}{$\begin{array}{l}\text { Participación } \\
\text { activa de la fa- } \\
\text { milia (integran- } \\
\text { tes), apoyando, } \\
\text { haciendo segui- } \\
\text { miento y deci- } \\
\text { diendo para avan- } \\
\text { zar en el proceso }\end{array}$} & Todos participan & 5 & \multirow{5}{*}{$\begin{array}{l}\text { Diálogo since- } \\
\text { ro con la fami- } \\
\text { lia campesina }\end{array}$} \\
\hline & & & $\begin{array}{l}\text { Padres, alguno de los hijos y otro } \\
\text { integrante }\end{array}$ & 4 & \\
\hline & & & $\begin{array}{l}\text { Padre y/o madre y alguno de los } \\
\text { hijos y/u otro integrante }\end{array}$ & 3 & \\
\hline & & & Solo un integrante & 2 & \\
\hline & & & $\begin{array}{l}\text { No hay integración de ningún } \\
\text { tipo }\end{array}$ & 1 & \\
\hline \multirow{5}{*}{$\begin{array}{l}\text { Deficiente grado } \\
\text { de producción } \\
\text { de alimentos } \\
\text { para el suminis- } \\
\text { tro familiar. }\end{array}$} & \multirow{5}{*}{$\begin{array}{l}\text { Autosuficiencia } \\
\text { alimentaria }\end{array}$} & \multirow{5}{*}{$\begin{array}{l}\text { Cantidad, cali- } \\
\text { dad, variedad y } \\
\text { disponibilidad } \\
\text { de alimentos } \\
\text { producidos y } \\
\text { consumidos en } \\
\text { la finca }\end{array}$} & $\begin{array}{l}80 \% \text { de alimentos producidos } \\
\text { durante todo el año }\end{array}$ & 5 & $\begin{array}{l}\text { Verificación } \\
\text { en campo }\end{array}$ \\
\hline & & & $\begin{array}{l}60 \text { al } 79 \% \text { de alimentos produci- } \\
\text { dos durante todo el año }\end{array}$ & 4 & $\begin{array}{l}\text { Registros de } \\
\text { producción }\end{array}$ \\
\hline & & & $\begin{array}{l}40 \text { al } 59 \% \text { de alimentos produci- } \\
\text { dos durante todo el año }\end{array}$ & 3 & $\begin{array}{l}\text { Registros de } \\
\text { compras }\end{array}$ \\
\hline & & & $\begin{array}{l}20 \text { al } 39 \% \text { de alimentos produci- } \\
\text { dos durante todo el año }\end{array}$ & 2 & $\begin{array}{l}\text { Evaluación de } \\
\text { dietas }\end{array}$ \\
\hline & & & $\begin{array}{l}\text { menos del } 19 \% \text { de alimentos pro- } \\
\text { ducidos durante todo el año }\end{array}$ & 1 & \\
\hline \multirow{5}{*}{$\begin{array}{l}\text { Prevalencia de } \\
\text { aplicaciones téc- } \\
\text { nicas basadas en } \\
\text { conocimientos } \\
\text { técnicos. }\end{array}$} & \multirow{5}{*}{$\begin{array}{l}\text { Aplicación de } \\
\text { conocimiento } \\
\text { agroecológico }\end{array}$} & \multirow{5}{*}{$\begin{array}{l}\text { Número de } \\
\text { prácticas, sabe- } \\
\text { res y experien- } \\
\text { cias agroecoló- } \\
\text { gicas aplicadas } \\
\text { en el predio para } \\
\text { avanzar en el } \\
\text { proceso de sus- } \\
\text { tentabilidad }\end{array}$} & $\begin{array}{l}11 \text { o más prácticas utilizadas per- } \\
\text { manentemente }\end{array}$ & 5 & $\begin{array}{l}\text { Verificación } \\
\text { en campo }\end{array}$ \\
\hline & & & $\begin{array}{l}8 \text { a } 10 \text { prácticas utilizadas perma- } \\
\text { nentemente }\end{array}$ & 4 & Registro \\
\hline & & & $\begin{array}{l}5 \text { a } 7 \text { prácticas utilizadas perma- } \\
\text { nentemente }\end{array}$ & 3 & \\
\hline & & & $\begin{array}{l}3 \text { a } 4 \text { prácticas utilizadas perma- } \\
\text { nentemente }\end{array}$ & 2 & \\
\hline & & & $\begin{array}{l}\text { Menos de } 2 \text { prácticas utilizadas } \\
\text { permanentemente }\end{array}$ & 1 & \\
\hline
\end{tabular}




\begin{tabular}{|c|c|c|c|c|c|}
\hline Punto crítico & $\begin{array}{l}\text { Nombre del } \\
\text { indicador }\end{array}$ & Concepto & \multicolumn{2}{|l|}{ Valoración } & $\begin{array}{l}\text { Cómo se } \\
\text { mide }\end{array}$ \\
\hline \multirow{5}{*}{$\begin{array}{l}\text { Pérdida de } \\
\text { biodiversidad }\end{array}$} & \multirow{5}{*}{ Biodiversidad } & \multirow{5}{*}{$\begin{array}{l}\text { Cantidad de } \\
\text { diseños y/o es- } \\
\text { tructuras en los } \\
\text { ecosistemas de } \\
\text { la finca }\end{array}$} & Todos los diseños & 5 & \multirow{5}{*}{$\begin{array}{l}\text { Verificación } \\
\text { en campo }\end{array}$} \\
\hline & & & $\begin{array}{l}\text { Sombrío diversificado, agrosil- } \\
\text { vopastoriles, cultivos asociados y } \\
\text { áreas de protección }\end{array}$ & 4 & \\
\hline & & & $\begin{array}{l}\text { Sombrío diversificado, cultivos } \\
\text { asociados y áreas de protección }\end{array}$ & 3 & \\
\hline & & & $\begin{array}{l}\text { Cultivos asociados y/o áreas } \\
\text { de protección }\end{array}$ & 2 & \\
\hline & & & Ningún diseño & 1 & \\
\hline \multirow{5}{*}{$\begin{array}{l}\text { Poca disponibi- } \\
\text { lidad de agua en } \\
\text { las fincas }\end{array}$} & \multirow{5}{*}{$\begin{array}{l}\text { Disponibilidad } \\
\text { de agua }\end{array}$} & \multirow{5}{*}{$\begin{array}{l}\text { Calidad, dispo- } \\
\text { nibilidad y apro- } \\
\text { vechamiento del } \\
\text { recurso hídrico } \\
\text { en la finca }\end{array}$} & $100 \%$ de disponibilidad & 5 & $\begin{array}{l}\text { Diálogo } \\
\text { directo con } \\
\text { el personal } \\
\text { del predio } \\
\end{array}$ \\
\hline & & & $\begin{array}{l}100 \% \text { de disponibilidad para con- } \\
\text { sumo humano y animal y } 60 \% \text { de } \\
\text { disponibilidad para cultivos }\end{array}$ & 4 & $\begin{array}{l}\text { Verificación } \\
\text { en campo }\end{array}$ \\
\hline & & & $\begin{array}{l}100 \% \text { para consumo humano; } \\
60 \% \text { para animales y cultivos }\end{array}$ & 3 & \\
\hline & & & $\begin{array}{l}100 \% \text { para consumo humano; } \\
60 \% \text { para animales }\end{array}$ & 2 & \\
\hline & & & $\begin{array}{l}\text { Dificultad de agua para } \\
\text { consumo humano }\end{array}$ & 1 & \\
\hline \multirow{5}{*}{$\begin{array}{l}\text { Incrementos vi- } \\
\text { sibles en los ni- } \\
\text { veles de erosión } \\
\text { de los suelos }\end{array}$} & \multirow{5}{*}{$\begin{array}{l}\text { Implementación } \\
\text { de prácticas para } \\
\text { la conservación } \\
\text { de suelos }\end{array}$} & \multirow{5}{*}{$\begin{array}{l}\text { Número de } \\
\text { prácticas imple- } \\
\text { mentadas para } \\
\text { la conservación } \\
\text { de suelos }\end{array}$} & $\begin{array}{l}\text { Implementación de } 60 \\
\text { más prácticas }\end{array}$ & 5 & \multirow{5}{*}{$\begin{array}{l}\text { Verificación } \\
\text { directa en } \\
\text { campo }\end{array}$} \\
\hline & & & Implementación de 5 prácticas & 4 & \\
\hline & & & Implementación de 3 prácticas & 3 & \\
\hline & & & Implementación de 2 prácticas & 2 & \\
\hline & & & Menor o igual a 1 práctica & 1 & \\
\hline \multirow{5}{*}{$\begin{array}{l}\text { Contaminación } \\
\text { generada por re- } \\
\text { siduos sólidos y } \\
\text { líquidos del be- } \\
\text { neficio del café. }\end{array}$} & \multirow{5}{*}{$\begin{array}{l}\text { Prácticas para } \\
\text { el manejo de } \\
\text { residuos sólidos } \\
\text { y líquidos }\end{array}$} & \multirow{5}{*}{$\begin{array}{l}\text { Número de } \\
\text { prácticas rea- } \\
\text { lizadas para el } \\
\text { manejo de resi- } \\
\text { duos a nivel de } \\
\text { la finca }\end{array}$} & $\begin{array}{l}\text { Implementación de } 6 \text { o más prác- } \\
\text { ticas ( } 4 \text { sólidos - } 2 \text { líquidos) }\end{array}$ & 5 & \multirow{5}{*}{$\begin{array}{l}\text { Verificación } \\
\text { en campo }\end{array}$} \\
\hline & & & $\begin{array}{l}\text { Implementación de } 5 \text { prácticas ( } 3 \\
\text { sólidos - } 2 \text { líquidos) }\end{array}$ & 4 & \\
\hline & & & $\begin{array}{l}\text { Implementación de } 3 \text { prácticas ( } 2 \\
\text { sólidos - } 1 \text { líquidos) }\end{array}$ & 3 & \\
\hline & & & $\begin{array}{l}\text { Implementación de } 2 \text { prácticas ( } 1 \\
\text { sólido - } 1 \text { líquido) }\end{array}$ & 2 & \\
\hline & & & Menor a 1 práctica & 1 & \\
\hline
\end{tabular}

Figura 2. Indicadores para la medición de la sustentabilidad en ACOC.

Evaluación de la sustentabilidad de los sistemas productivos campesinos de la Asociacion de Caficultores Orgánicos de Colombia - ACOC- Valle del Cauca 
La escala empleada para la medición de los indicadores fue construida en un rango de 1 a 5; siendo 1 el valor más bajo y 5 el más alto. Se organizó en niveles que determinaron la mayor o menor sustentabilidad del indicador y las categorías desde muy baja hasta ideal (figura 3).

\begin{tabular}{|c|c|c|}
\hline Niveles de medición & Valoración cualitativa & Categorías \\
\hline $1-1.99$ & Muy Bajo & Muy baja sustentabilidad \\
\hline $2-2.99$ & Bajo & Baja sustentabilidad \\
\hline $3-3.99$ & Medio & Medianamente sustentable \\
\hline $4-4.5$ & Alto & Altamente sustentable \\
\hline $4.6-5$ & Ideal & Sustentabilidad Ideal \\
\hline
\end{tabular}

Figura 3. Niveles de medición y categorías de la sustentabilidad

Algunos indicadores requirieron relacionar las escalas de medición con listados de referencia de los valores de la escala construidos por los agricultores como acuerdos para la sustentabilidad regional (figura 4). Los listados de referencia se realizaron para aquellos indicadores que necesitaban describir procesos, prácticas, variedad de alimentos y tipos de diseños entre otros. Para la selección de cada uno de ellos fueron necesarias varias sesiones de discusión grupal, que finalmente permitieron determinar los aspectos más relevantes de medición dentro de cada indicador.

\begin{tabular}{|c|c|c|c|}
\hline Indicador & Observación & Lista de referen & para la evaluación \\
\hline $\begin{array}{l}\text { Planificación y } \\
\text { Registros }\end{array}$ & $\begin{array}{l}\text { El grupo base de investi- } \\
\text { gadores y los agricultores } \\
\text { participantes en la prime- } \\
\text { ra fase determinaron que } \\
\text { las herramientas necesarias } \\
\text { para ordenar, implementar y } \\
\text { evaluar las actividades en la } \\
\text { finca son las que aparecen en } \\
\text { la columna contigua. }\end{array}$ & $\begin{array}{l}\text { Diagnóstico predial } \\
\text { Registro de compras } \\
\text { y ventas } \\
\text { Diagrama } \\
\text { de sustentabilidad } \\
\text { Cronograma } \\
\text { de actividades }\end{array}$ & $\begin{array}{l}\text { Cronograma de activi- } \\
\text { dades } \\
\text { Costos de producción } \\
\text { Diagnóstico predial } \\
\text { Registro de compras } \\
\text { y ventas }\end{array}$ \\
\hline $\begin{array}{l}\text { Agrodiversidad } \\
\text { sustentable }\end{array}$ & $\begin{array}{l}\text { Los grupos de especies vege- } \\
\text { tales y animales, selecciona- } \\
\text { dos durante el desarrollo del } \\
\text { proyecto, como necesarios } \\
\text { para el fortalecimiento de } \\
\text { los sistemas productivos en } \\
\text { el campo de la agrodiversi- } \\
\text { dad fueron: }\end{array}$ & $\begin{array}{l}\text { Frutales } \\
\text { Granos } \\
\text { Hortalizas } \\
\text { Pastos y forrajes } \\
\text { Medicinales } \\
\text { y aromáticas }\end{array}$ & $\begin{array}{l}\text { Raíces y tubérculos } \\
\text { Animales menores (pe- } \\
\text { ces, conejos, cuyes) } \\
\text { Animales mayo- } \\
\text { res (vacas, caballos, } \\
\text { cerdos, burros) }\end{array}$ \\
\hline
\end{tabular}




\begin{tabular}{|c|c|c|c|}
\hline Indicador & Observación & Lista de referencia & para la evaluación \\
\hline $\begin{array}{l}\text { Autosuficiencia } \\
\text { alimentaria }\end{array}$ & $\begin{array}{l}\text { Para la comunidad cam- } \\
\text { pesina de la ACOC estuvo } \\
\text { claro que al hablar de auto- } \\
\text { suficiencia alimentaria no } \\
\text { solo es necesario garantizar } \\
\text { la producción de alimen- } \\
\text { tos, sino también conseguir } \\
\text { que los mismos se provean } \\
\text { en la calidad, la cantidad, la } \\
\text { disponibilidad y la variedad } \\
\text { suficientes para la alimenta- } \\
\text { ción del grupo familiar du- } \\
\text { rante todo el año. } \\
\text { Se presenta el listado de ali- } \\
\text { mentos que fueron consi- } \\
\text { derados como básicos para } \\
\text { lograr la autosuficiencia ali- } \\
\text { mentaria de la familia. } \\
\text { La producción y consumo } \\
\text { de estos alimentos en las fin- } \\
\text { cas campesinas fue evalua- } \\
\text { da positivamente, en tanto } \\
\text { su producción se garantice } \\
\text { durante por lo menos once } \\
\text { meses del año. }\end{array}$ & $\begin{array}{l}\text { Maíz (Zea mays) } \\
\text { Fríjol (Phaseolus spp) } \\
\text { Cebolla (Allium cepa) } \\
\text { Zanahoria } \\
\text { (Daucus carota) } \\
\text { Repollo } \\
\text { (Brassica oleracea) } \\
\text { Leche } \\
\text { Carne } \\
\text { Yuca } \\
\text { (Manihot esculenta) } \\
\text { Arveja (Pisum sativum) }\end{array}$ & $\begin{array}{l}\text { Panela }^{4} \\
\text { Tomate (Lycopersi- } \\
\text { cum esculentum) } \\
\text { Chocolate } \\
\text { Habichuela } \\
\text { (Phaseolus spp) } \\
\text { Papa } \\
\text { (Solanum tuberosum) } \\
\text { Huevos } \\
\text { Plátano (Musa spp) } \\
\text { Frutas } \\
\text { Medicinales }\end{array}$ \\
\hline $\begin{array}{l}\text { Aplicación de los } \\
\text { conocimientos } \\
\text { adquiridos }\end{array}$ & $\begin{array}{l}\text { A continuación se listan las } \\
\text { prácticas agroecológicas que } \\
\text { fueron seleccionadas por } \\
\text { los agricultores como nece- } \\
\text { sarias para garantizar que } \\
\text { en las fincas se estuvieran } \\
\text { aplicando, de manera per- } \\
\text { manente, los conocimientos } \\
\text { adquiridos en los procesos } \\
\text { de acompañamiento y capa- } \\
\text { citación recibidos. }\end{array}$ & $\begin{array}{l}\text { Cultivos asociados } \\
\text { Protección } \\
\text { de nacimientos } \\
\text { Recuperación y conser- } \\
\text { vación de semillas } \\
\text { Uso de coberturas } \\
\text { Sombrío diversificado } \\
\text { Sistema silvopastoril }\end{array}$ & $\begin{array}{l}\text { Control biológico de } \\
\text { plagas y enfermedades } \\
\text { Uso de productos } \\
\text { subutilizados } \\
\text { Cercas vivas } \\
\text { Alimentación alternati- } \\
\text { va animal }\end{array}$ \\
\hline
\end{tabular}

4. Alimento elaborado a partir de jugo de caña de azúcar, conocido también como piloncillo, raspadura, rapadura, atado dulce, panetela, tapa de dulce, chancaca, empanizao, papelón o panocha. 


\begin{tabular}{|c|c|c|c|}
\hline Indicador & Observación & Lista de referenci & para la evaluación \\
\hline Biodiversidad & $\begin{array}{l}\text { Para que cada uno de los } \\
\text { sistemas productivos perte- } \\
\text { necientes a la ACOC fuera } \\
\text { considerado como biodiver- } \\
\text { so, los agricultores seleccio- } \\
\text { naron los siguientes diseños } \\
\text { y/o estructuras que conside- } \\
\text { raron necesarios para cum- } \\
\text { plir con el indicador. }\end{array}$ & $\begin{array}{l}\text { Silvopastoriles } \\
\text { Agrosilvopastoriles } \\
\text { Cultivos asociados }\end{array}$ & $\begin{array}{l}\text { Áreas protegidas } \\
\text { Fuentes de agua } \\
\text { protegidas }\end{array}$ \\
\hline $\begin{array}{l}\text { Implementación } \\
\text { de prácticas para } \\
\text { la conservación de } \\
\text { suelos }\end{array}$ & $\begin{array}{l}\text { Las siguientes prácticas } \\
\text { fueron escogidas por la } \\
\text { comunidad, para llevar a } \\
\text { cabo la evaluación de la } \\
\text { conservación de suelos en } \\
\text { cada uno de los agroecosis- } \\
\text { temas campesinos. }\end{array}$ & $\begin{array}{l}\text { Sombríos permanentes } \\
\text { Manejo de trinchos } \\
\text { Coberturas muertas } \\
\text { Manejo de terrazas } \\
\text { Labranza animal } \\
\text { Curvas a nivel }\end{array}$ & $\begin{array}{l}\text { Selección de } \\
\text { arvenses nobles } \\
\text { Barreras vivas } \\
\begin{array}{l}\text { Utilización de } \\
\text { abonos verdes } \\
\text { Aplicación de materia } \\
\text { orgánica }\end{array}\end{array}$ \\
\hline $\begin{array}{l}\text { Prácticas para el } \\
\text { manejo de resi- } \\
\text { duos sólidos y } \\
\text { líquidos }\end{array}$ & $\begin{array}{l}\text { A continuación se describen } \\
\text { las prácticas definidas como } \\
\text { necesarias para realizar un } \\
\text { manejo sustentable de los } \\
\text { residuos sólidos y líquidos } \\
\text { producto de los ciclos y } \\
\text { procesos propios de los sis- } \\
\text { temas productivos. }\end{array}$ & $\begin{array}{l}\text { Clasificación de resi- } \\
\text { duos } \\
\text { Utilización de fosas } \\
\text { Reciclaje de residuos } \\
\text { inorgánicos }\end{array}$ & $\begin{array}{l}\text { Uso de pozo séptico } \\
\text { Manejo de biodiges- } \\
\text { tores } \\
\text { Canales de estabiliza- } \\
\text { ción de aguas servidas } \\
\text { Compostaje }\end{array}$ \\
\hline
\end{tabular}

Figura 4. Listados de referencia y escalas de medición

Con el fin de establecer la confiabilidad del instrumento de medición se llevó a cabo prueba piloto en dos fincas de la Asociación. 


\section{Índices de sustentabilidad}

Los índices de sustentabilidad se obtuvieron como los promedios del conjunto de indicadores de cada finca (Tabla 1):

Tabla 1. Índices de Sustentabilidad de las fincas de ACOC 2005 - 2010

\begin{tabular}{|c|c|c|c|c|}
\hline $\mathbf{N}^{o}$ & Vereda & Nombre de la finca & \begin{tabular}{|c|} 
Índice de susten- \\
tabilidad 2015
\end{tabular} & $\begin{array}{c}\text { Índice de sustenta- } \\
\text { bilidad } 2010\end{array}$ \\
\hline \multicolumn{5}{|c|}{ Restrepo } \\
\hline 1 & Calimita & La Gaviota & 3.73 & 3.36 \\
\hline 2 & San Pablo & La Estrella & 2.55 & 3.00 \\
\hline 3 & La Fresneda & La Gaviota & 2.73 & 3.91 \\
\hline 4 & Cachimbal & La Soledad & 3.91 & 4.36 \\
\hline 5 & San Pablo & Miravalle & 2.55 & 3.73 \\
\hline 6 & Diamante & La Colina & 2.82 & 4.36 \\
\hline 7 & La Soledad & El Jardín & 3.45 & 3.64 \\
\hline 8 & Calimita & El Carmen & 2.91 & 3.00 \\
\hline 9 & San Pablo & El Vergel & 2.91 & 4.27 \\
\hline 10 & La Merced & La Fortuna & 3.64 & 3.36 \\
\hline 11 & Las Brisas & Bellavista & 3.36 & 3.00 \\
\hline \multicolumn{5}{|c|}{ Buga } \\
\hline 12 & $\begin{array}{l}\text { Cordobita } \\
\text { (Yotoco) }\end{array}$ & La Esperanza & 3.55 & 3.27 \\
\hline 13 & La Unión & La Esperanza & 3.36 & 3.09 \\
\hline 14 & La Unión & El Porvenir & 4 & 4.00 \\
\hline 15 & El Diamante & La Fortuna & 4 & 4.09 \\
\hline 16 & Guadalejo & Villa María & 3.55 & 4.45 \\
\hline \multicolumn{5}{|c|}{ Riofrío } \\
\hline 17 & Calabazas & Las Camelias & 3.36 & 2.45 \\
\hline 18 & Calabazas & Buenavista & 3.45 & 2.82 \\
\hline 19 & $\begin{array}{l}\text { Mir a valle } \\
\text { Bajo }\end{array}$ & El Recuerdo & 3.64 & 3.64 \\
\hline 20 & $\begin{array}{l}\text { San José de la } \\
\text { selva }\end{array}$ & El Bosquesito & 2.91 & 3.36 \\
\hline 21 & $\begin{array}{l}\text { Miravalle } \\
\text { Bajo }\end{array}$ & Alto Bonito & 2.64 & 2.45 \\
\hline
\end{tabular}




\begin{tabular}{|l|l|l|l|l|}
\hline $\mathbf{N} \mathbf{N}^{\mathbf{0}}$ & \multicolumn{1}{|c|}{ Vereda } & Nombre de la finca & $\begin{array}{c}\text { Índice de susten- } \\
\text { tabilidad 2015 }\end{array}$ & $\begin{array}{c}\text { Índice de sustenta- } \\
\text { bilidad 2010 }\end{array}$ \\
\hline 22 & $\begin{array}{l}\text { Dos quebra- } \\
\text { das }\end{array}$ & El Rescate & 3.18 & 2.82 \\
\hline 23 & Calabazas & Buenavista & 3.27 & 2.55 \\
\hline \multicolumn{5}{|c|}{ Fenicia } \\
\hline 24 & Guayabal & $\begin{array}{l}\text { El Silencio (La Valen- } \\
\text { tina) }\end{array}$ & 3.27 & 3.09 \\
\hline 25 & Guayabal & La Floresta & 3.55 & 3.91 \\
\hline 26 & Guayabal & La Plegaria & 3.27 & 3.45 \\
\hline 27 & La Vigorosa & El Vergel & 3.09 & 3.00 \\
\hline 28 & La Vigorosa & El Vergel & 3.64 & 3.91 \\
\hline 29 & Los Alpes & Patio Bonito & 2.91 & 2.91 \\
\hline 30 & La Judea & La Estela No 2 & 3.91 & 3.45 \\
\hline
\end{tabular}

El análisis de correspondencias múltiples permitió determinar los indicadores que mayores variaciones presentaron en las dos mediciones. Este análisis dividió la población de las fincas de la ACOC en tres grupos, logrando explicar el 81.97\% de la variabilidad total encontrada. Los grupos fueron: el grupo 1, compuesto por quince fincas; el grupo 2, por doce fincas y el grupo 3 , por tres fincas (Figura 5).

Indicadores que presentaron variaciones importantes en los tres grupos

En el análisis de correspondencias múltiples los indicadores que presentaron variaciones importantes en los dos ciclos fueron: Biodiversidad, Agrodiversidad Sustentable y Autosuficiencia Alimentaria.

\section{Biodiversidad}

Este indicador presentó variaciones en su composición: catorce fincas se encuentran en niveles entre ideales y altos entre 4.6 y 5; esto significa que los sistemas productivos poseen cinco diseños o arreglos de especies vegetales y animales: sistemas silvopastoriles, agrosilvopastoriles, cultivos asociados, áreas protegidas y fuentes de agua protegidas. En cinco fincas la biodiversidad se valoró en un nivel medio ya que presentaron entre 4 y 6 grupos o estructuras de biodiversidad; once fincas se encuentran en un nivel bajo pues solo tienen entre 2 y 3 grupos (de los ocho establecidos en el listado de referencia), con solo dos especies vegetales cultivadas. 


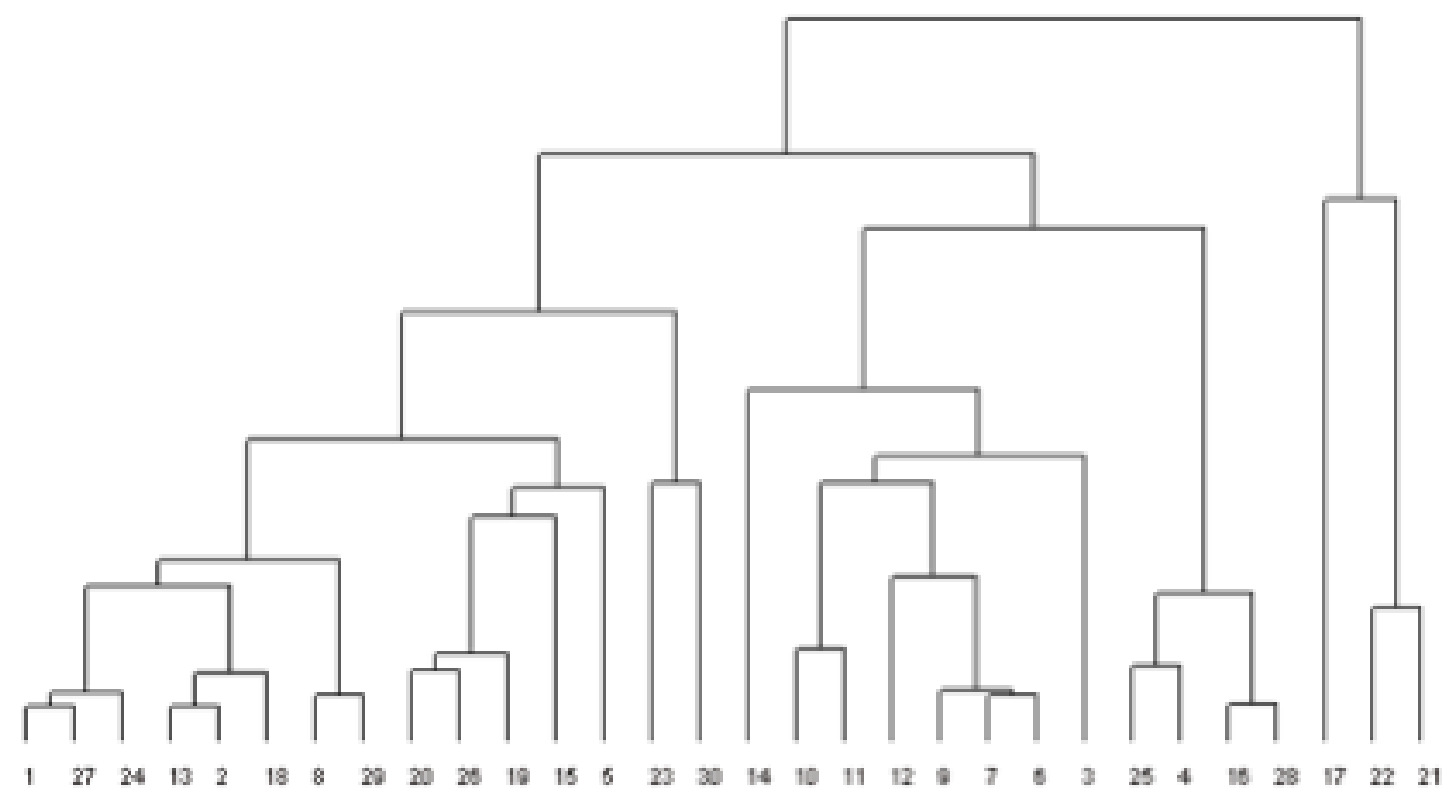

Figura 5. Resultado del análisis clúster para la agrupación de fincas de acuerdo a resultados de los indicadores.

\section{Agrodiversidad sustentable}

Este indicador presentó variaciones en su valoración: catorce fincas tuvieron una calificación media, ya que cuentan con cinco diseños o arreglos de especies animales y vegetales: silvopastoriles, agrosilvopastoriles, cultivos asociados, áreas protegidas y fuentes de agua protegidas. Nueve fincas presentan una valoración ideal, pues tienen establecidos ocho grupos o arreglos con tres especies vegetales y dos especies animales cada uno. En cuatro fincas la valoración fue alta y en dos la valoración fue baja pues la agrodiversidad está dada entre dos y tres grupos con especies agrícolas y pecuarias establecidas en asociación. En general se observa un nivel medio para este indicador, lo cual indica la gran cantidad de especies animales y vegetales cultivadas en las fincas.

\section{Autosuficiencia alimentaria}

La valoración ideal del indicador está dada por un listado de dieciocho alimentos cuya producción y consumo cumple con las necesidades nutricionales para el grupo familiar. En la ACOC, catorce fincas presentan una valoración media para la autosuficiencia alimentaria, lo que significa que la alimentación de la familia está dada por la producción y el consumo de entre el 40 y el 59\% de los alimentos requeridos durante todo el año en la cantidad, calidad, variedad y disponibilidad requerida por la familia. Cuatro fincas presentan una autosuficiencia alimentaria alta, significando que que en ellas se produce 
y consume entre el 60 y el 79\% de los alimentos requeridos por la familia. En ellas no solo se garantiza la producción de los dieciocho alimentos a que se refiere el indicador, sino que también se encuentran en la calidad, cantidad, disponibilidad y variedad suficientes durante todo el año; sólo tres fincas poseen valoraciones bajas y muy bajas, pues solo producen entre el 20 y el $39 \%$ de los alimentos que requiere la familia.

\section{Indicadores que presentaron evaluaciones altas e ideales}

\section{Disponibilidad de Agua}

En ambas evaluaciones el indicador presentó una evaluación del 90\% entre ideal y alta para veintisiete fincas; esto significa que los sistemas productivos de la asociación cuentan con el recurso agua en la calidad, disponibilidad y aprovechamiento tanto para consumo humano y animal como para los cultivos durante todo el año. Sólo tres fincas presentaron niveles medios.

\section{Implementación de prácticas para la conser- vación de suelos}

En el 93.33\% de las fincas de la ACOC se presenta una valoración entre ideal y alta (4.6 - 5) para este indicador. En veintiocho fincas se llevan a cabo entre 8 y 10 prácticas para la conservación del suelo: sombríos permanentes, manejo de trinchos, coberturas muertas, manejo de terrazas, selección de arvenses nobles, labranza animal, curvas a nivel, barreras vivas, utiliza- ción de abonos verdes y aplicación de materia orgánica. Solo en dos fincas el indicador tiene una valoración media.

\section{Integración de la Familia al proceso}

En dieciocho familias de la ACOC que corresponden al 60\%; todos los integrantes de la familia (padre, madre e hijos) participan activamente apoyando, haciendo seguimiento y decidiendo de manera colectiva para avanzar en el proceso de sustentabilidad. En seis fincas se presentó una valoración media porque participan el padre, la madre y uno de los hijos; y en otras seis fincas solo participa un integrante de la familia, que en la mayoría de los casos es el padre.

\section{Aplicación de los conocimientos adquiridos}

El 90\% de las familias de la ACOC aplican entre 8 y 10 prácticas, saberes y experiencias agroecológicas de las diez que fueron definidas como necesarias para garantizar la sustentabilidad de los sistemas productivos, y fueron aprendidas en los procesos de capacitación y acompañamiento recibido: biopreparados, cultivos asociados, control biológico, protección de nacimientos, uso de productos subutilizados, uso de coberturas, cercas vivas, cultivos diversificados, sistemas silvopastoriles y alimentación animal alternativa. 


\section{Indicadores que presentaron valoraciones medias}

\section{Prácticas para el manejo de residuos sólidos y líquidos}

El indicador presentó para el 67\% de las fincas (20 de ellas) valoraciones entre altas e ideales; esto significa que las familias implementan más de cinco prácticas para el manejo de residuos sólidos y líquidos (cuatro para sólidos y dos para líquidos). Ocho fincas (27\%) presentaron una valoración media porque implementan más de tres prácticas.

\section{Ingresos diversificados}

Este indicador presentó una valoración entre baja y muy baja para el trece fincas: el $43.33 \%$ de los sistemas productivos, esto muestra que entre 70 y $90 \%$ de los ingresos de las familias dependen del cultivo del café, y otro renglón productivo que genera ingresos complementarios entre el 10 y el 30\%. Otras doce fincas que corresponden (40\%) presentaron niveles entre altos e ideales; al contrario de las trece anteriores, el 50\% los ingresos se perciben por el cultivo del café y el resto se obtiene por otros tres renglones productivos.

\section{Indicadores que presentaron valoraciones bajas}

\section{Productividad de Café}

Fue el indicador que presentó las más bajas valoraciones, entre 1 y 1.99 para veintiséis fincas (87\%). Esto quiere decir que producen menos de diecinueve arrobas de café pergamino seco por plaza al año. Tres fincas presentan un nivel medio lo que significa que producen entre 40 y $59 \%$ arrobas de café pergamino seco al año. Solo una presentó un nivel ideal.

\section{Planificación y registros}

Diecinueve fincas (63.33\%) tienen evaluaciones entre bajas y muy bajas para este indicador, porque las familias solo llevan registros de compras y ventas. Seis fincas (20\%) presentan valoraciones entre altas e ideales porque además de los registros de compras y ventas manejan diagnóstico predial, cronograma de actividades, registro de compras y ventas, costos de producción y diagrama de sustentabilidad. Solo cinco fincas (17\%) presentaron niveles entre altos e ideales.

Comparación de los resultados de los índices de sustentabilidad y los indicadores en las dos evaluaciones 2005 - 2010

La sustentabilidad para los grupos uno y tres presentó una reducción durante los cinco años que transcurrieron entre las dos evaluaciones; esto puede observarse al comparar los índices de sustentabilidad para cada grupo (tabla 2). La reducción del índice general de la sustentabilidad para el Grupo 1 es del 1.8\%, y para el Grupo 3 del 15.8\%. El Grupo 2 presentó un incremento del $13.2 \%$. 
Tabla 2. Índices generales de la sustentabilidad en la ACOC años 2005 y 2010

\begin{tabular}{|c|c|c|c|}
\hline Grupos & $\begin{array}{c}\text { Índices de } \\
\text { sustentabilidad 2005 }\end{array}$ & $\begin{array}{c}\text { Índices de } \\
\text { sustentabilidad 2010 }\end{array}$ & $\begin{array}{c}\text { Aumento } \\
\text { y/o disminución }\end{array}$ \\
\hline Grupo 1 & 3.30 & 3.24 & $-1.8 \%$ \\
\hline Grupo 2 & 3.42 & 3.87 & $13.2 \%$ \\
\hline Grupo 3 & 3.06 & 2.58 & $-15.8 \%$ \\
\hline
\end{tabular}

Al comparar los resultados de los indicadores en los dos ciclos de medición se encontró que un conjunto de cuatro indicadores mantuvo evaluaciones entre altas y medias para los dos períodos: Disponibilidad de agua, implementación de prácticas para la conservación de suelos y aplicación de los conocimientos adquiridos con un leve aumento. La integración de la familia al proceso bajó de una valoración ideal a una media, ya que presentó una disminución de 0.8 .

Los indicadores Productividad del café y Planificación y registros presentaron valoraciones entre bajas y muy bajas para ambas evaluaciones; presentándose una disminución leve para ambos de 0.3 en la medición del 2010.

El indicador de Ingresos diversificados mantuvo el mismo nivel medio en ambas evaluaciones.

El indicador de Autosuficiencia alimentaria paso de un nivel bajo en el 2005 a un nivel medio en el 2010 con un aumento de 0.8. El mismo comportamiento presentó el indicador de Prácticas para el manejo de residuos sólidos y líquidos que pasó de un nivel bajo a uno medio con un aumento de 0.9 para el 2010.
Los indicadores de Autosuficiencia alimentaria y Prácticas para el manejo de residuos sólidos y líquidos pasaron de niveles bajos a niveles medios en la evaluación del 2010: el primero aumento 0.8 y el segundo 0.9 .

Los indicadores de Biodiversidad y Agrodiversidad sustentable tuvieron disminuciones en la medición del 2010 (0.5 para ambos).

En general al comparar los indicadores en los dos ciclos de medición se encontraron comportamientos similares en lo que tiene que ver con los niveles o categorías, registrándose un aumento leve en cinco de ellos: Disponibilidad de agua, Aplicación de los conocimientos adquiridos, Autosuficiencia Alimentaria, Prácticas para la conservación de suelos y Prácticas para el manejo de residuos sólidos y líquidos. Cinco presentaron disminuciones: Productividad de café, Planificación y registros, Integración de la familia al proceso, Biodivesidad y Agrodiversidad Sustentable. El indicador de Ingresos diversificados mantuvo la misma evaluación en ambos ciclos de medición (Figura 6). 


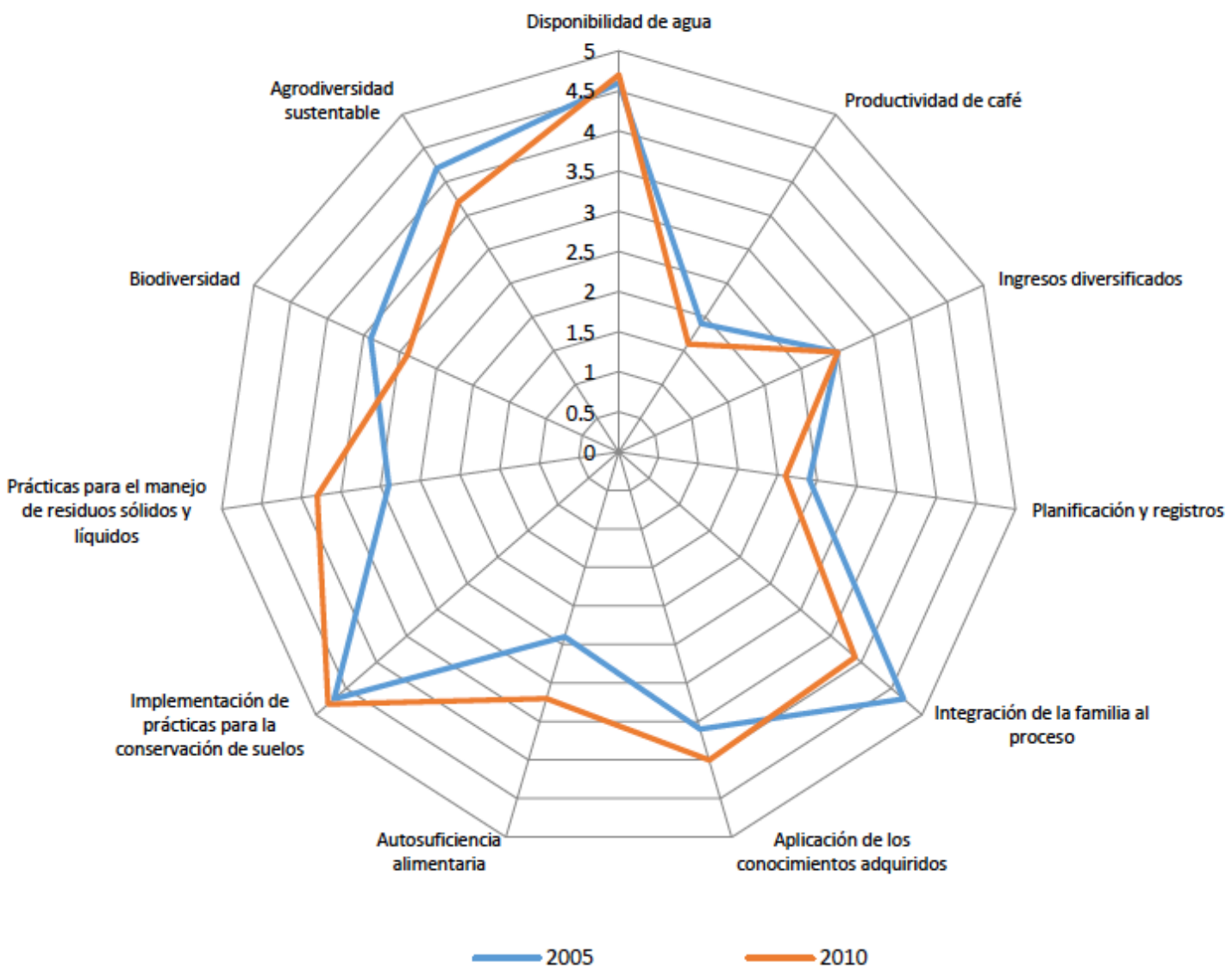

Figura 6. Índices de sustentabilidad por indicador 2005 - 2010.

La evaluación de sustentabilidad en las fincas campesinas pertenecientes a la ACOC mostró una serie de criterios clave para la sustentabilidad predial, relacionadas con las prácticas tradicionales y los subsistemas que se articulan en fincas campesinas. El análisis realizado mostró cómo en los cinco años que transcurrieron entre los dos ciclos de evaluación, los cambios en estos sistemas productivos no fueron muy relevantes: se mantuvo una constante en la práctica cultural sustentable combinada con el saber tradicional y el desarrollo de capacidades de organización y autogestión.
Cabe destacar que aun cuando la evaluación se realizó en dos momentos diferentes, el interés se centró en conocer su evolución en el tiempo; para este caso, cinco años; entendiéndose que la sustentabilidad no es una situación de momento o una condición estática, sino que corresponde a un proceso verificable sólo con el transcurso del tiempo; implicando que su evaluación deba realizarse mediante análisis periódicos, en los cuales los registros se convierten en evidencias sustantivas, indicativas de dicha condición (Toro et al, 2010). 
Son cuatro los indicadores que hacen parte de los recursos del sistema: Biodiversidad y la Agrodiversidad sustentable que presentaron una disminución en el último ciclo de evaluación. La biodiversidad pasó así de un nivel medio a uno bajo, lo cual quiere decir que los diseños o estructuras establecidas en las fincas han disminuido con relación a los cinco criterios establecidos para medir este indicador. Los otros dos indicadores que hacen parte de los recursos del sistema son los relacionados con el manejo del agua y el suelo, los cuales mostraron evaluaciones entre ideales y altas en los dos ciclos de medición. Esto indica que las fincas campesinas de la ACOC presentan un buen nivel de sustentabilidad en el componente ambiental, y que a través del tiempo, han diseñado estructuras y arreglos dentro de las fincas que permiten relacionar elementos de manejo del predio, un adecuado aprovechamiento de los espacios y el ciclaje de nutrientes, que aseguren la circulación de flujos ecológicos y el uso eficiente de recursos.

Por su parte dos indicadores relacionados con la operación del sistema mantuvieron en los dos ciclos de evaluación una baja sustentabilidad, es el caso de la Productividad del café y la Planificación y registros. Las evaluaciones para estos dos indicadores siempre estuvieron en niveles de muy baja o baja sustentabilidad; la razón de estas evaluaciones se explica por la incidencia o afectación que tienen factores externos tales como el mercado, los precios y el transporte sobre el trabajo de las familias campesinas y las presiones que ejerce el medio. Esto adicional a la renuencia conocida de los agricultores a planificar las actividades el predio y a llevar registros.

Fueron tres los indicadores relacionados con la operación del sistema que presentaron niveles altos e ideales, y hacen parte del componente sociocultural: la Integración de familia al proceso y la Aplicación de los conocimientos adquiridos. Esto denota el esfuerzo familiar por alcanzar mejores condiciones de vida a partir de los activos que poseen tales como mano de obra y conocimientos tradicionales. La Autosuficiencia alimentaria presentó un aumento importante, pasó de un nivel bajo a un nivel medio. Esto quiere decir que, en general, en las fincas de la ACOC se produce entre el 40 y el 59\% de los alimentos consumidos durante todo el año; lo cual es muy significativo tratándose de predios de menos de 10ha que producen en condiciones tan adversas.

El indicador de Ingresos diversificados no tuvo cambios en los dos ciclos de medición, lo que indica que los ingresos de las familias de la ACOC están conformados entre un 50 y un $60 \%$ por las ventas de café y por la venta de dos o tres renglones productivos diferentes al café.

El indicador relacionado con la aplicación de Prácticas para el manejo de residuos sólidos y líquidos paso de un nivel bajo a uno medio, 
lo que muestra el esfuerzo de las familias por implementar tres prácticas de manejo de residuos sólidos y líquidos.

De acuerdo con los resultados de este estudio puede afirmarse que los agricultores de la ACOC mantienen en su repertorio de operación de los sistemas de manejo un conjunto de prácticas orientadas a un manejo sustentable, destacándose aspectos relacionados con los componentes técnico-productivo, socio cultural y ambiental.

En las treinta fincas evaluadas durante los dos períodos, los indicadores relacionados con los recursos del sistema tuvieron niveles de sustentabilidad entre medios, altos e ideales; es decir, la sustentabilidad de la ACOC en lo que corresponde al componente ambiental es alta a ideal. En lo que corresponde a los indicadores que hacen parte de la operación del sistema se observó que dos de ellos - que corresponden a los componentes económico y técnico productivo - ameritan acciones correctivas: Productividad del café y Planificación y registros. Dos indicadores del componente sociocultural presentaron niveles altos e ideales: Integración de la familia al proceso y Aplicación de los conocimientos adquiridos; la Autosuficiencia alimentaria denota un aumento importante en su desempeño.

Es importante indicar que la valoración más alta de cada indicador señala un horizonte que puede ser no alcanzable para algunos sis- temas de manejo, puesto que existen factores que pueden limitarlo como el tamaño de las fincas, el acceso a recursos, la escasez de mano de obra, entre otros aspectos de índole externa.

\section{Conclusiones}

La aplicación de la metodología MESMIS, durante los dos ciclos de medición, permitió analizar el comportamiento de los indicadores, señalando el rumbo de los cambios de la sustentabilidad de los sistemas productivos analizados.

Los cambios en la sustentabilidad de la ACOC durante las dos evaluaciones estuvieron marcados, básicamente, por los indicadores de Agrodiversidad, Biodiversidad y Autosuficiencia alimentaria e Integración de la familia al proceso. En los cinco años que transcurrieron entre los dos ciclos de evaluación, los cambios en la sustentabilidad no fueron notables; sin embargo, se reporta el aumento en seis indicadores, la disminución en otros cinco y el mismo nivel en uno.

La evaluación permitió una mirada integral y holística de los sistemas, detectando situaciones de orden social y ambiental externos que están afectando la sustentabilidad del sistema productivo.

Las fincas con índices de sustentabilidad altos tienden a mantenerse por su capacidad 
de generar condiciones socioeconómicas y ecológicas adecuadas, lo que en consecuencia justifica el mantenimiento y mejora de los sistemas de manejo en las condiciones tecnológicas conscientemente construidas.

Las familias campesinas de la ACOC presentan un alto grado de apropiación y control local, cohesión social y trabajo grupal, lo que refleja los atributos de autodependencia y autogestión.

Las complejas relaciones entre los indicadores y los atributos de los sistemas de manejo campesino denotan una variada cantidad de posibilidades y de condicionantes técnicos y socioeconómicos, que están sustentados en una vasta base de conocimientos característicos de la agricultura familiar campesina y de una perspectiva de conservación de la base de los recursos de la producción (agua, suelo, biodiversidad).

Se agradece al IMCA Instituto Mayor Campesino, Buga, Colombia. A Álvaro Idárraga por sus aportes incondicionales; a Martha Liliana Muñoz y Luz Deny Tulcán, estudiantes de la Especialización en Agroecología Tropical Andina de UNISARC.

\section{Referencias}

Acevedo, A. y Angarita, A. (2013). Metodología para la evaluación de sustentabilidad a partir de indicadores locales para el diseño y desarrollo de programas agroecológicos, MESILPA. Bogotá: Corporación Universitaria Minuto de Dios, UNIMINUTO.

Acevedo, A. (2000). Evaluación de Agroecosistemas Campesinos empleando Indicadores de Sustentabilidad. Tesis de Maestría en Agroecología y Desarrollo Rural Sostenible. La Rábida, Huelva España: Universidad Internacional de Andalucía. Sede Iberoamericana.

Astier, M. (2000). Fortalecimiento de una metodología de evaluación de sustentabilidad a través de un estudio de caso en la región Purhepecha, México. GIRAA.C. En: http:// www.rimisp. org/FCKeditor/UserFiles/File/documentos/docs/pdf/propuesta4_mexico.pdf ; consulta: abril de 2013.

Astier, M.; Masera, O. y Galván-Miyoshi, Y. (2008). Evaluación de sustentabilidad, un enfoque dinámico y multidimensional. Barcelona: Fundación Instituto de Agricultura Ecológica y Sustentable.

Astier, M.; Masera, O. y López Ridaura, S. (1999). Sustentabilidad y manejo de recursos naturales. El marco de evaluación MESMIS. México: GIRA-Mundi-prensa. 
Astier, M.; Perez-Agis, E.; Mota, F.; Masera, O. y Alatorre, C. (2000). El Diseño de Sistemas sustentables de maíz en la Región Purhépecha. P. 271-320. En: Masera, O. y López - Riduara, S. (Eds.). Sustentabilidad y Sistemas Campesinos: cinco experiencias de evaluación en el México rural. México: GIRA.

Cáceres, M. (2008). La Sustentabilidad de los Sistemas Campesinos analizada desde dos Enfoques: Estados vs. Procesos. Agriculture Journals. 33: 8, p. 578 -585.

Cardoza, R. (2003). Una experiencia de producción y comercialización agroecológica en el Valle del Alto Piura. LEISA, Revista de Agroecología. Ocho estudios de caso. Edición especial: $53-57$.

Delgadillo, J. y Delgado, F. (2003). Evaluación de la Implementación de Prácticas de Conservación de suelos: El caso de la comunidad Chullpa K’asa, Bolivia. LEISA, Revista de Agroecología. Ocho estudios de caso. Edición especial: 24-31.

Demo, P. (2009). Investigación participante: mito y realidad. Buenos Aires: Lumen.

Fallas, G.; Chacón, M. y Castro, J. (2009). Sustentabilidad de sistemas agrícolas de fincas ecológicas y tradicionales en Costa Rica. Research Journal of the Costa Rican Distance Education University. Vol. 1(2): 441-457.

Fals-Borda, O. y Mohammad, A.R. (Eds). (1991). Action and knowledge: breaking the monopoly with participatory action research. New York: Apex Press.

Galván - Miyoshi, Y.; Masera, O. y López, S. (2008). Temas estratégicos en las Evaluaciones de Sustentabilidad. En: Evaluación de Sustentabilidad: un enfoque dinámico y multidimensional. Madrid: IMAG.

Gomes de Almeida, S. y Bianconi, G. (2003). Monitoreo económico de la transición agroecológica: estudio de caso de una propiedad familiar del sur de Brasil. LEISA, Revista de Agroecología. Ocho estudios de caso. Edición especial: 58 - 63.

Grupo Semillas. (2004). Producción y comercialización orgánica y agroecológica - proyecto de vida campesina, la Asociación de Caficultores Orgánicos de Colombia ACOC. Conservación y Uso sostenible de la biodiversidad, derechos colectivos y soberanía alimentaria. Semillas Revista No.21. En: http:// semillas .org.co; consulta: Noviembre 2013. 
Hernández, R. (1994). Teorías sobre Campesinado en América Latina: Una Evaluación Crítica. Revista Chilena de Antropología. 12: 179-200.

López-Ridaura, S.; Masera, O. y Astier, M. (2002). Evaluating the sustainability of complex socio-environmental systems. The MESMIS framework. Ecological Indicators. 2, 135-148.

Masera, O. Astier, M. López-Ridaura, S. (1999). Sustentabilidad y manejo de recursos naturales; el marco de evaluación MESMIS. Grupo Interdisciplinario de tecnología rural apropiada. México.

Masera, O. (2008). El proyecto de evaluación de sustentabilidad MESMIS. En: Evaluación de Sustentabilidad: un enfoque dinámico y multidimensional. Madrid: IMAG.

Petersen, P. (2003). Evaluando la sustentabilidad: estudios de caso sobre impactos de innovaciones agroecológicas en la agricultura familiar de diferentes países latinoamericanos. LEISA, Revista de Agroecología. Ocho estudios de caso. Edición especial: 24-31.

Toro, P.; García, A.; Gómez - Castro, A.G.; Perea, J.; Acero, R. y Rodríguez - Estévez, V, (2010). Evaluación de la Sustentabilidad en Agroecosistemas. Archivos de Zootecnia: 71-94.

Van der Ploeg, J.D. (2010). Nuevos Campesinos: Campesinos e Imperios Alimentarios. Barcelona: Icaria. 